\title{
Novel oral anticoagulants for stroke prevention in atrial fibrillation: a focus on the older patient
}

\author{
This article was published in the following Dove Press journal: \\ International Journal of General Medicine \\ 20 March 2013 \\ Number of times this article has been viewed
}

\section{Scott W Yates \\ Center for Executive Medicine, Plano, TX, USA}

\begin{abstract}
Atrial fibrillation (AF) is a common arrhythmia that is associated with an increased risk of stroke, particularly in the elderly. Traditionally, a vitamin $\mathrm{K}$ antagonist such as warfarin is prescribed for stroke prevention. Warfarin is effective at lowering stroke risk but has several limitations due to food restrictions, drug interactions, and a narrow therapeutic window. Various novel oral anticoagulants (NOACs) are available or under development to provide alternative treatment options. This article reviews the efficacy and safety of three NOACs (dabigatran etexilate, rivaroxaban, and apixaban) in addition to warfarin and aspirin, for prevention of stroke in patients with $\mathrm{AF}$, focusing on the elderly population. Results of clinical trials demonstrate that the efficacy of NOACs for stroke prevention in patients with AF is as good as or better than that of warfarin. The NOACs are also associated with an equivalent or lower risk of bleeding. Regardless of the medication chosen, older patients with AF must be treated cautiously due to an increased risk of stroke and bleeding, as well as potential challenges related to drug interactions and monitoring requirements. NOACs may be suitable alternatives to warfarin for stroke prevention in older patients due to several advantages, including a faster onset of action, few drug or food interactions, and no requirement for regular monitoring. However, dose adjustments may be required for certain patients, such as those with severe renal impairment or in the setting of drug interactions.
\end{abstract}

Keywords: aspirin, warfarin, dabigatran etexilate, rivaroxaban, apixaban

\section{Introduction}

Atrial fibrillation (AF) is a common cardiac arrhythmia and a well-established risk factor for stroke. ${ }^{1,2}$ Patients with AF have a four- to five-times greater risk of stroke or transient ischemic attack compared with those without $\mathrm{AF}^{1,3}$ In addition, strokes that occur in patients with AF are associated with an increased risk of premature death and disability. ${ }^{4-10}$

AF is an especially important concern among older adults. Prevalence of AF increases with patient age (Figure 1$)^{3,11}$ and, in the USA, approximately $82 \%$ of patients with AF are $\geq 65$ years old and $37 \%$ are $\geq 80$ years old. ${ }^{3}$ The rate of stroke in patients with AF increases substantially in patients aged 80-89 years, with an attributable risk of $23.5 \% .{ }^{1}$ As age increases, the risk of complications from stroke increases. The $\mathrm{CHADS}_{2}$ score - calculated based on presence of Congestive heart failure (either systolic or diastolic), Hypertension, Age $\geq 75$ years, Diabetes mellitus, and history of Stroke or transient ischemic attack - is used to estimate a patient's long-term risk of stroke. ${ }^{12}$ Points are assigned to each of the included risk factors, with two points assigned for history of stroke, and total scores range from 0 (low risk) to 6 (high risk).
Correspondence: Scott W Yates Center for Executive Medicine, 6020 W Parker Road, Suite 420 Plano, TX 75093, USA

Tel + I 972244 I 300

Fax + | 972244 |30|

Emailswyates@texasmed.com 




Prevalence of AF Incidence of stroke

Figure I Impact of atrial fibrillation (AF) by increasing age: overall prevalence of AF and annual incidence of stroke in patients with AF.

Notes: Line indicates the prevalence of AF with increasing age as a percentage of the general population of US adults. Prevalence is plotted on the primary axis and is based on data from Go et al. Copyright ( ) (200I) American Medical Association. All rights reserved. Adapted with permission from Go AS, Hylek EM, Phillips KA, et al. Prevalence of diagnosed atrial fibrillation in adults: national implications for rhythm management and stroke prevention: the AnTicoagulation and Risk Factors in Atrial Fibrillation (ATRIA) Study. JAMA. 200I;285(18):2370-2375. ${ }^{3}$ Bars provide the incidence of stroke among patients with AF, expressed as a percentage of patients with AF per year. Stroke incidence is plotted on the secondary axis and is based on data from Wolf et al. Copyright @) (I987) American Medical Association. All rights reserved. Adapted with permission from Wolf PA, Abbott RD, Kannel WB. Atrial fibrillation: a major contributor to stroke in the elderly. The Framingham Study. Arch Intern Med. 1987; | 477(9): I56|-1564.94

A modified version of the $\mathrm{CHADS}_{2}$, the $\mathrm{CHA}_{2} \mathrm{DS}_{2}$ -VASc score, considers the following additional risk factors for stroke in patients with AF: vascular disease (such as myocardial infarction [MI], complex aortic plaque, and peripheral artery disease), female sex, and age $65-74$ years. ${ }^{13}$ The $\mathrm{CHA}_{2} \mathrm{DS}_{2}$-VASc score places greater emphasis on age $\geq 75$ years by assigning two points to this risk factor. Because the prevalence of many of the risk factors included in $\mathrm{CHADS}_{2}$ and $\mathrm{CHA}_{2} \mathrm{DS}_{2}$-VASc also increases with age, ${ }^{14-16}$ age is a dichotomous variable in the calculation of $\mathrm{CHADS}_{2}$ and $\mathrm{CHA}_{2} \mathrm{DS}_{2}$-VASc scores.

Stroke prevention in patients with AF focuses on anticoagulant agents, including warfarin (a vitamin $\mathrm{K}$ antagonist), which effectively reduce the risk of stroke by preventing blood clots from forming. However, warfarin has a narrow therapeutic window, is associated with an increased risk of bleeding including intracranial hemorrhage ( $\mathrm{ICH})$, and requires frequent monitoring. ${ }^{17}$ These limitations have prompted the development of a novel group of anticoagulants, which may be particularly helpful when considering stroke prevention in elderly patients with AF.

\section{Use of warfarin for stroke prevention in older patients}

Many clinical trials have demonstrated the efficacy of warfarin for stroke prevention in patients with AF. Warfarin-treated patients were $61 \%$ less likely to have a stroke and $66 \%$ less likely to have an ischemic stroke than patients in control groups. ${ }^{18}$ Anticoagulant treatment remains effective in older patients with AF. ${ }^{19}$ An analysis of almost 9000 patients with AF found that the benefit of oral anticoagulation in the prevention of stroke was maintained regardless of patient age. When viewed relative to the increase in stroke risk in older patients, these investigators concluded that the absolute benefit of anticoagulation increases as patients age. ${ }^{19}$

Despite its efficacy, many patients with $\mathrm{AF}$ ( $50 \%$ or more) do not receive warfarin and remain at high risk of stroke. ${ }^{20-22}$ In the USA, only approximately one-third of office-based patient visits for AF included a mention of warfarin. ${ }^{23}$ Potential contraindications are the most frequently cited reason for why warfarin is not prescribed. However, study conclusions vary on the extent to which true, rather than perceived, 
contraindications prevent warfarin treatment, particularly in elderly patients. ${ }^{20,21,24}$ Among patients without contraindications to warfarin therapy, only $22 \%$ were prescribed warfarin in an observational study across five European countries. ${ }^{21}$ Although some retrospective studies of charts or databases have found higher proportions $(55 \%)$, it is clear that many patients who are candidates for anticoagulation do not receive treatment. ${ }^{2,25}$

Multiple studies have found that patients of advanced age are less likely to receive anticoagulation therapy than younger patients (Figure 2). ${ }^{20,24-26} \mathrm{~A}$ retrospective review of hospital admissions for ischemic stroke in patients with AF found that $75 \%$ of patients aged $<75$ years received anticoagulation therapy compared with only $33 \%$ of patients aged $>85$ years. ${ }^{25}$ Similarly, a prospective study found decreasing rates of anticoagulation therapy with increasing age: $75 \%$ of patients aged $65-69$ years, $59 \%$ of patients aged $70-79$ years, $45 \%$ of patients aged $80-89$ years, and $24 \%$ of patients aged $\geq 90$ years were treated with warfarin. ${ }^{20}$

Limited use of anticoagulation is attributed to a number of difficulties with warfarin, including drug interactions (Table 1), risk of bleeding, and dietary restrictions, as well as variability in patient response (eg, due to factors such as age, renal clearance, ethnicity, and genetic variability). ${ }^{20,21,27-29}$ The requirement for frequent monitoring can be a barrier and some patients may be unwilling to undertake treatment. ${ }^{30}$ Amid these challenges, compliance with warfarin use has also been shown to decline over time. In a study of 1005 adults with AF in which $65 \%$ were prescribed warfarin, only $44 \%$ were still taking it 30 months later. ${ }^{31}$

When warfarin is prescribed, the level of anticoagulation achieved varies, and this affects treatment effectiveness. Maintaining an international normalized ratio (INR) between two and three provides efficacy in reducing stroke risk and minimizes the excess risk of bleeding. ${ }^{31,32}$ Patients with an INR less than two have a significantly greater risk of ischemic stroke; patients with an INR greater than three are at a significantly increased risk of bleeding compared with those within the INR range of two to three. ${ }^{31}$ Evidence from metaanalyses of clinical trials and cohort studies indicates that patients receiving warfarin spend, on average, only $51 \%-64 \%$ of the time in this therapeutic range. ${ }^{33,34}$ The amount of time spent in the therapeutic range is directly linked to the risk of stroke in patients aged $\geq 70$ years. ${ }^{35}$

A further restriction on appropriate warfarin use in patients of advanced age is the limited ability of riskstratification schemes to predict stroke risk in patients aged $\geq 75$ years $^{36}$ and perceived difficulty assessing when the benefits of anticoagulation outweigh the risks. ${ }^{37}$ Several risk-stratification scoring systems to assess risk of bleeding with warfarin treatment have been developed. These include: HAS-BLED (Hypertension, Abnormal renal/ liver function, Stroke, Bleeding history or predisposition, Labile INR, Elderly [ $\geq 65$ years], and concomitant Drug/alcohol use), ${ }^{38} \mathrm{HEMORR}_{2}$ HAGES (Hepatic or renal disease, Ethanol abuse, Malignancy, Older age, Reduced

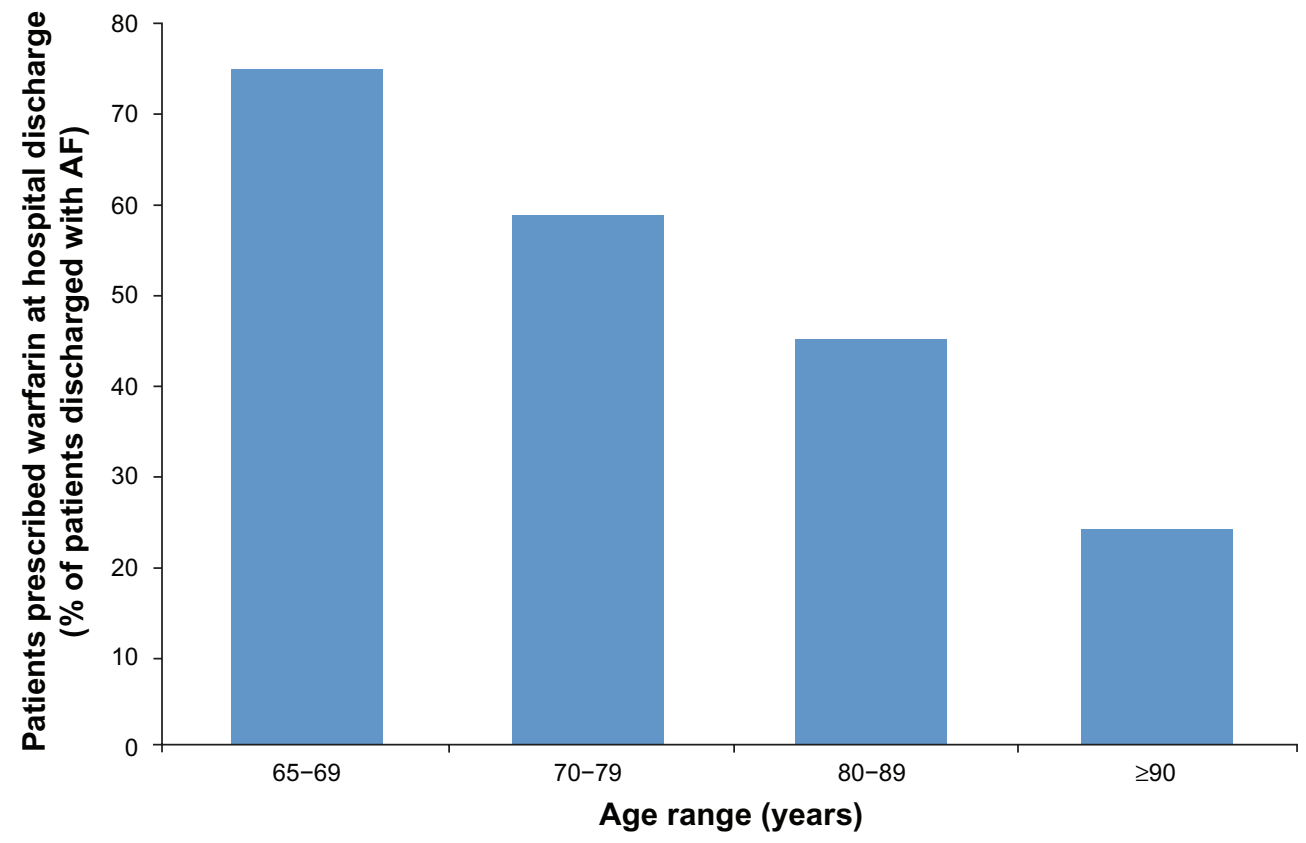

Figure 2 Rates of anticoagulation by patient age group.

Notes: Proportion of patients admitted with electrocardiography-verified atrial fibrillation (AF) who were prescribed warfarin therapy at hospital discharge by patient age. Data from Hylek et al. ${ }^{20}$ 
Table I Summary of drug-drug interactions for warfarin and the novel oral anticoagulants dabigatran, rivaroxaban, and apixaban

\begin{tabular}{|c|c|}
\hline Anticoagulant agent & Drug-drug interactions \\
\hline Warfarin ${ }^{27}$ & $\begin{array}{l}\text { Do not use with } \\
\text { - Drugs used for thrombosis treatment or prophylaxis, or other drugs with adverse effects on hemostasis } \\
\text { - Fibrinolytic drugs } \\
\text { - St John's wort } \\
\text { Use caution with } \\
\text { - Alcohol } \\
\text { - Inhibitors of CYP2C9, IA2, or } 3 \text { A4 and drugs known to potentiate the effects of warfarin, including: acetaminophen, } \\
\text { allopurinol, amiodarone, antibiotics (eg, ciprofloxacin, erythromycin, metronidazole, sulfamethoxazole), azole } \\
\text { antimycotics }{ }^{\mathrm{b}} \text {, caffeine, statins (excluding pravastatin), tamoxifen } \\
\text { - Inducers of CYP2C9, IA2, or } 3 \text { A4 and drugs known to antagonize the effect of warfarin, including: azathioprine, } \\
\text { barbiturates, carbamazepine, griseofulvin, rifampin, phenytoin, primidone } \\
\text { - NSAIDs, platelet aggregation inhibitors, heparins, other antithrombotic agents } \\
\text { - Oral contraceptives } \\
\text { - Serotonergic agents, including SSRIs and SNRIs } \\
\text { - Antidepressants }\end{array}$ \\
\hline Dabigatran $^{54}$ & $\begin{array}{l}\text { Avoid coadministration with } \\
\text { - P-gp inducer rifampin } \\
\text { - In patients with moderate renal impairment ( } \mathrm{CrCl} 30-50 \mathrm{~mL} / \mathrm{min}) \text {, consider a reduced dose (75 mg twice daily) } \\
\text { if coadministered with P-gp inhibitors dronedarone and systemic ketoconazole } \\
\text { Concomitant use of drugs affecting hemostasis increases the risk of bleeding, including drugs such as } \\
\text { - NSAIDs used chronically } \\
\text { - Antiplatelet agents, heparin, or fibrinolytic therapy }\end{array}$ \\
\hline Rivaroxaban ${ }^{55}$ & $\begin{array}{l}\text { Avoid concomitant use with } \\
\text { - Combined P-gp and strong CYP3A4 inducers (eg, rifampin, phenytoin, carbamazepine, phenobarbital, or St John's wort) } \\
\text { - Combined P-gp and strong CYP3A4 inhibitors (eg, azole antimycotics }{ }^{b} \text { or HIV protease inhibitors) } \\
\text { Concomitant use of other drugs affecting hemostasis increases the risk of bleeding, including drugs such as } \\
\text { - Aspirin, platelet aggregation inhibitors, other antithrombotic agents } \\
\text { - NSAIDs }\end{array}$ \\
\hline Apixaban $^{56}$ & $\begin{array}{l}\text { Avoid concomitant use with } \\
\text { - Strong dual inducers of CYP3A4 and P-gP (eg, rifampin, phenytoin, carbamazepine, or St John's wort) } \\
\text { Decrease dose of apixaban when coadministered with } \\
\text { - Strong dual inhibitors of CYP3A4 and P-gP (eg, azole antimycotics }{ }^{b} \text { or HIV protease inhibitors }{ }^{c} \text { ) } \\
\text { Concomitant use of drugs affecting hemostasis increases the risk of bleeding, including drugs such as } \\
\text { - NSAIDs used chronically } \\
\text { - Platelet aggregation inhibitors or other antithrombotic agents } \\
\text { - SSRIs or SNRIs }\end{array}$ \\
\hline
\end{tabular}

Notes: aWarfarin is associated with a number of drug-drug and drug-food interactions. Consult the prescribing information for warfarin and any drugs used concurrently for a complete list. ${ }^{\mathrm{A}} \mathrm{Azole}$ antimycotics include ketoconazole, itraconazole, voriconazole, and posaconazole. If apixaban is coadministered with drugs that are strong dual inhibitors of CYP3A4 and P-gp, the dose of apixaban should be decreased to $2.5 \mathrm{mg}$ twice daily. In patients already taking a reduced dose of apixaban, concomitant use of apixaban with strong dual inhibitors of CYP3A4 and P-gP should be avoided.

Abbreviations: $\mathrm{CrCl}$, creatinine clearance; CYP, cytochrome P450; HIV, human immunodeficiency virus; NSAID, non-steroidal anti-inflammatory drug; P-gp, P-glycoprotein; SNRI, serotonin/norepinephrine reuptake inhibitor; SSRI, selective serotonin reuptake inhibitor.

platelet count or function, Re-bleeding, Hypertension, Anemia, Genetic factors, Excessive fall risk and Stroke), ${ }^{39}$ or that developed in the Anticoagulation and Risk Factors in Atrial Fibrillation (ATRIA) study (anemia, severe renal disease, age $\geq 75$ years, previous hemorrhage, and diagnosed hypertension). ${ }^{40} \mathrm{~A}$ study comparing the predictive performance of these tools in patients with AF undergoing anticoagulation showed that the HAS-BLED, HEMORR $_{2}$ HAGES and ATRIA scores had only modest performance in predicting any clinically relevant bleeding, though the HAS-BLED score performed better than the other two. Only HAS-BLED was significantly predictive of $\mathrm{ICH}^{4}{ }^{41}$
Beyond considering advanced age as a contraindication to warfarin, fear of elderly patients falling (leading to an increased risk of bleeding and $\mathrm{ICH}$ ) is a frequently cited reason why clinicians do not prescribe anticoagulant therapy to older patients. This perceived risk of bleeding or ICH due to falls appears to be higher than the actual risk. ${ }^{42-44}$ Similarly, although clinicians may hesitate to use warfarin in elderly patients with cognitive impairment, mild-to-moderate cognitive impairment does not necessarily interfere with warfarin use ${ }^{45}$ Caution is warranted, however, as bleeding risk with warfarin treatment does increase with age. Among patients treated with warfarin, the relative risk of a life-threatening bleeding 
event in patients aged $\geq 80$ years was 4.5 (95\% confidence interval $[\mathrm{CI}], 1.3,15.6)$ when compared with patients aged $<50$ years. ${ }^{46}$

\section{Aspirin as an alternative to warfarin in older patients}

Age is an independent risk factor for stroke, and complications from stroke increase as patients with AF age. This should increase the likelihood of preventive treatment but warfarin is under-prescribed in the elderly. ${ }^{25}$ Due to the bleeding risks associated with warfarin, physicians may prefer to prescribe aspirin for stroke prevention in patients with $\mathrm{AF}^{20,36}$ Among 405 inpatients with AF, aged 65 years or older, 199 (49\%) did not receive warfarin on discharge and physicians preferred to prescribe aspirin in approximately $70 \%$ of these patients. ${ }^{20}$ Guidelines include recommendations for the use of aspirin for stroke prevention in AF; however, these recommendations are generally restricted to patients considered to be at low risk for stroke or those with contraindications to the use of warfarin. ${ }^{47-49}$

Although viewed by many clinicians as an alternative to warfarin, the efficacy of antiplatelet treatment with aspirin for stroke reduction is limited. Pooled clinical trial data show a $21 \%$ reduction in the relative risk of stroke with aspirin ${ }^{49}$ and a study in low-risk patients with AF observed that aspirin might be no better than placebo for reducing thromboembolic events and may be associated with an increased risk of major bleeding. ${ }^{50}$ Trials comparing aspirin and warfarin have found aspirin treatment to be less effective in stroke prevention and to cause more bleeding events than treatment with warfarin. ${ }^{51,52}$ Similar limitations to aspirin therapy were found in patients of advanced age ( $\geq 75$ years or $80-90$ years). ${ }^{52,53}$ The Birmingham Atrial Fibrillation Treatment of the Aged (BAFTA) trial demonstrated the superiority of warfarin over aspirin in reducing the risk of ischemic stroke in patients with AF aged $\geq 75$ years. ${ }^{52}$ The risk of stroke was reduced by $54 \%(P=0.003)$ and the combined risk of fatal or disabling stroke (ischemic or hemorrhagic), $\mathrm{ICH}$, or clinically significant embolism was reduced by $52 \%$ in the warfarin group compared with the aspirin group $(P=0.003)$, with no difference in major bleeding events. Aspirin therapy is further limited in older patients because the efficacy of aspirin seems to decline beyond the age of 70 years, whereas the risk of bleeding increases. ${ }^{19}$

\section{Novel oral anticoagulants in AF}

Limitations and concerns associated with warfarin therapy and lack of efficacy associated with aspirin therapy have led to the development of novel oral anticoagulants (NOACs), including dabigatran (a direct thrombin inhibitor), ${ }^{54}$ rivaroxaban $^{55}$ and apixaban ${ }^{56}$ (direct factor Xa inhibitors). Edoxaban is another direct factor Xa inhibitor that is currently in latestage clinical trials. ${ }^{57}$

Updated guidelines from the American College of Chest Physicians recommend oral anticoagulation in patients with $\mathrm{AF}$ at intermediate $\left(\mathrm{CHADS}_{2}\right.$ score of 1$)$ or high $\left(\mathrm{CHADS}_{2}\right.$ score of $\geq 2$ ) risk of stroke. ${ }^{58}$ In such patients, the American College of Chest Physicians guidelines recommend use of dabigatran $150 \mathrm{mg}$ twice daily rather than dose-adjusted warfarin $^{59}$; however, it should be noted that these guidelines were published prior to the approval of rivaroxaban and apixaban.

While dabigatran, rivaroxaban, and apixaban are all novel anticoagulants that are administered orally, clinical trial data provide some differentiation between these treatments (Table 2).

\section{Dabigatran etexilate: RE-LY}

Dabigatran is a direct inhibitor of thrombin, the enzyme that converts soluble fibrinogen into insoluble strands of fibrin. ${ }^{55}$ The inhibition of thrombin prevents the formation of blood clots and, therefore, is an effective mechanism for anticoagulation.

The Randomized Evaluation of Long-term anticoagulation therapY (RE-LY) trial ${ }^{60,61}$ included 18,113 patients with AF who were at risk of stroke. The study subjects were randomized into three groups and received double-blinded dabigatran (150 or $110 \mathrm{mg}$ ) or open-label adjusted-dose warfarin. Patients had a mean age of 71 years and a mean $\mathrm{CHADS}_{2}$ score of 2.1 .

In RE-LY, dabigatran $150 \mathrm{mg}$ twice daily was associated with a $35 \%$ reduction in the relative risk of stroke or systemic embolism ( $P<0.001$ for superiority) and a similar rate of major bleeding compared with warfarin. ${ }^{60,61}$ The rate of ischemic or unspecified stroke was $0.92 \%$ per year for dabigatran $150 \mathrm{mg}$ and $1.21 \%$ per year for warfarin $(P=0.03)$, and the rate of hemorrhagic stroke was $0.10 \%$ per year in the dabigatran $150 \mathrm{mg}$ group compared with $0.38 \%$ per year in the warfarin group $(P<0.001)$. The rate of ICH was significantly lower for dabigatran $150 \mathrm{mg}$ than with warfarin $(0.32 \%$ vs $0.76 \%$ per year; $P<0.001)$. A lower dose of dabigatran (110 mg twice daily) was associated with a similar rate of stroke or systemic embolism compared with warfarin, but a lower rate of major bleeding. The rate of all-cause mortality was $4.13 \%$ per year in the warfarin group compared with $3.64 \%$ per year with $150 \mathrm{mg}$ of dabigatran $(P=0.051)$ and $3.75 \%$ per year with $110 \mathrm{mg}$ of dabigatran $(P=0.13)$. 





In patients aged $\geq 75$ years, dabigatran $(150 \mathrm{mg}$ )-treated patients had lower rates of stroke and systemic embolism (relative risk, $0.67 ; 95 \% \mathrm{CI}, 0.49,0.90$ ) than warfarin-treated patients, and there was no significant difference in the rate of major bleeding (relative risk, 1.18 ; $95 \% \mathrm{CI}, 0.98,1.42$ ). ${ }^{62}$ Rates of stroke and hemorrhage were compared in subgroups aged $<75$ years and $\geq 75$ years: for dabigatran $150 \mathrm{mg}$, the rate of stroke or systemic embolism was $0.90 \%$ per year in patients aged $<75$ years compared with $1.43 \%$ per year in patients aged $\geq 75$ years. A similar difference between age groups was found among warfarin-treated patients $(1.43 \%$ per year in patients aged $<75$ years; $2.14 \%$ per year in patients aged $\geq 75$ years). However, based on these age subgroups ( $<75$ and $\geq 75$ years) the interaction between age and treatment for the outcome of stroke or systemic embolism was not significant $(P=0.81)$.

The interaction between age and treatment for major bleeding was significant $(P<0.001) .{ }^{62}$ Dabigatran $150 \mathrm{mg}$ twice daily compared with warfarin was associated with a lower risk of major bleeding in patients aged $<75$ years (2.12\% vs $3.04 \%$ per year; $P<0.001)$.

For patients aged $\geq 75$ years, the risk of ICH was lower in dabigatran-treated patients $(0.41 \%$ per year for dabigatran $150 \mathrm{mg}$ vs $1.00 \%$ per year for warfarin). ${ }^{62}$ Patients aged $<75$ years had ICH rates of $0.26 \%$ per year for dabigatran $150 \mathrm{mg}$ and $0.61 \%$ per year for warfarin. However, the test for interaction between age and treatment for ICH was not significant $(P=0.92)$.

The risk of MI in patients taking dabigatran has been investigated in a number of analyses. In RE-LY, the relative risk of MI was increased by $38 \%$ in patients treated with dabigatran $150 \mathrm{mg}$ compared with warfarin $(P=0.048) .{ }^{60}$ However, a re-analysis of the RE-LY results, including newly identified events, found no significant increase in MI among dabigatran-treated patients compared with warfarin-treated patients (relative risk, $1.27 ; P=0.12$ ). ${ }^{61}$ A meta-analysis of seven dabigatran trials, across different indications, investigated risk of MI or acute coronary syndrome (ACS) associated with dabigatran. The analysis found that the risk of MI or ACS with dabigatran compared with warfarin was increased by $33 \%(P=0.03)$ based on the original RE-LY results, and increased by $27 \%(P=0.05)$ when the newly identified events from the RE-LY trial were added to this analysis. ${ }^{63} \mathrm{~A}$ post-hoc analysis of the RE-LY results investigated risk of MI and risk of cardiac events based on an expanded definition, including MI, unstable angina, coronary artery bypass grafting, percutaneous coronary intervention, cardiac arrest, and cardiac death. ${ }^{64}$ The analysis demonstrated no significant increase in MI with dabigatran compared with warfarin (hazard ratio [HR], 1.27; $P=0.12$ ). Using the expanded definition of cardiac events, there was no statistically significant difference in event rates between the dabigatran $150 \mathrm{mg}$ twice daily and warfarin groups (HR, $0.98 ; P=0.77$ ).

While the results from RE-LY demonstrated that both the $150 \mathrm{mg}$ and $110 \mathrm{mg}$ twice daily doses of dabigatran were safe and effective, the US Food and Drug Administration (FDA) approved only the $150 \mathrm{mg}$ dose of dabigatran twice daily. ${ }^{65}$ The FDA attempted to find a population for whom a lower dose would yield a more favorable balance between risks and benefits, given that dabigatran $110 \mathrm{mg}$ twice daily demonstrated only non-inferiority in the overall population. Use of lower doses in patients with advanced age, impaired renal function, or a history of hemorrhage was considered, but the FDA did not find an improved benefit-risk profile with the lower dose. In assessing the benefit-risk profile, the benefit of superior efficacy in the prevention of stroke and systemic embolism with dabigatran $150 \mathrm{mg}$ twice daily and the lack of a subgroup for whom a lower dose decreased risks led the FDA to approve only the $150 \mathrm{mg}$ dose of dabigatran.

\section{Rivaroxaban: ROCKET-AF}

Rivaroxaban is a highly selective, direct factor Xa inhibitor taken orally once daily with the evening meal $(20 \mathrm{mg})$. Inhibition of factor Xa prevents the development of thrombin, thereby disrupting the coagulation cascade and preventing the formation of blood clots. ${ }^{55}$

The Rivaroxaban Once daily oral direct factor Xa inhibition Compared with vitamin $\mathrm{K}$ antagonism for prevention of stroke and Embolism Trial in Atrial Fibrillation (ROCKET-AF) ${ }^{66}$ was a double-blinded global study. It included patients with AF and a history of prior stroke, transient ischemic attack, or nonneurologic systemic embolism. Patients received $20 \mathrm{mg}$ of rivaroxaban or dose-adjusted warfarin. In total, 14,264 patients with a median age of 73 years and a mean $\mathrm{CHADS}_{2}$ score of 3.5 were assessed.

In ROCKET-AF, rivaroxaban was non-inferior to warfarin for the prevention of stroke (ischemic or hemorrhagic) or systemic embolism (HR for the intention-to-treat population, $0.88 ; 95 \% \mathrm{CI}, 0.75,1.03 ; P<0.001$ for non-inferiority) ${ }^{66}$ Rates of major bleeding were not significantly different between the rivaroxaban and warfarin safety populations. There was no significant difference in the rate of ischemic stroke between treatment groups $(P=0.58)$; 
the rate of hemorrhagic stroke was $0.26 \%$ per year in the rivaroxaban group and $0.44 \%$ per year in the warfarin group $(P=0.02)$. Rates of MI were similar between treatment groups $(P=0.12)$. The rate of ICH was significantly reduced for rivaroxaban compared with warfarin $(0.5 \% \mathrm{vs}$ $0.7 \%$ per year; HR, 0.67; 95\% CI, 0.47, 0.93; $P=0.02$ ). In the intention-to-treat population, the rate of all-cause mortality did not differ between groups $(P=0.15)$.

A sub-analysis of ROCKET-AF investigated the efficacy and safety of rivaroxaban in patients aged $\geq 75$ years, and investigators noted that the results for older patients were consistent with the overall study results. ${ }^{67}$ There was no significant interaction between treatment and age for major bleeding ( $P=0.34$ for interaction). Rates of major bleeding in patients aged $\geq 75$ years were $4.86 \%$ per year in the rivaroxaban group and $4.40 \%$ per year in the warfarin group, compared with $2.69 \%$ and $2.79 \%$ per year for patients aged $<75$ years in the rivaroxaban and warfarin groups, respectively. Clinically relevant non-major bleeding was significantly higher for patients aged $\geq 75$ years compared with patients aged $<75$ years $(P=0.01)$. Based on the rates of $\mathrm{ICH}$ in patients aged $\geq 75$ years $(0.66 \%$ per year rivaroxaban vs $0.83 \%$ per year warfarin) and in patients aged $<75$ years $(0.37 \%$ per year rivaroxaban vs $0.68 \%$ per year warfarin), there was no significant interaction for $\mathrm{ICH}$ $(P=0.27$ for interaction).

\section{Apixaban}

Apixaban is a highly selective direct factor $\mathrm{Xa}$ inhibitor that binds directly to factor $\mathrm{Xa}$, preventing amplification of the coagulation process. Thrombin cannot be activated and clotting does not occur. Apixaban is taken orally, $5 \mathrm{mg}$ twice daily. ${ }^{56}$

\section{ARISTOTLE}

The Apixaban for Reduction In STroke and Other ThromboemboLic Events in atrial fibrillation (ARISTOTLE) trial included patients with non-valvular AF. ${ }^{68}$ Patients had one or more risk factors for stroke and received either apixaban (5 mg twice daily) or dose-adjusted warfarin. Patients randomized to treatment with apixaban received $2.5 \mathrm{mg}$ twice daily if they met at least two of the following criteria: age $\geq 80$ years, weight $\leq 60 \mathrm{~kg}$, and/or a serum creatinine level $\geq 1.5 \mathrm{mg} / \mathrm{dL}$. A total of 18,201 patients with a median age of 70 years and a mean $\mathrm{CHADS}_{2}$ score of 2.1 participated in the double-blinded trial.

In ARISTOTLE, apixaban reduced the risk of stroke or systemic embolism by $21 \%$ compared with warfarin; the effect of apixaban was statistically significant $(P=0.01)$ and demonstrated superiority of apixaban over warfarin for this primary outcome. ${ }^{68}$ The rate of ischemic or uncertain strokes was similar in the two treatment arms. However, the rate of hemorrhagic stroke was significantly reduced in the apixaban group ( $0.24 \%$ per year) compared with the warfarin group $(0.47 \%$ per year; HR, $0.51 ; 95 \% \mathrm{CI}, 0.35$, $0.75 ; P<0.001)$.

The rate of major bleeding was $31 \%$ lower with apixaban (2.13\% per year) compared with warfarin $(3.09 \%$ per year; HR, $0.69 ; 95 \%$ CI, $0.60,0.80 ; P<0.001)$, and the rate of ICH was significantly reduced with apixaban versus warfarin ( $0.33 \%$ vs $0.80 \%$ per year; HR, $0.42 ; 95 \%$ CI, $0.30,0.58$; $P<0.001) .{ }^{68}$ Rates of MI were similar between treatment groups $(P=0.37)$. All-cause mortality was significantly lower with apixaban than with warfarin $(3.52 \%$ vs $3.94 \%$ per year; HR, 0.89; 95\% CI, 0.80, 0.998; $P=0.047)$.

Overall, in the older patient subgroups (65-74 years and $\geq 75$ years), the reductions in stroke and systemic embolism and in major bleeding with apixaban compared with warfarin were statistically significant and consistent with findings in the overall study population. Within the $<65$ years age group, the differences between treatment groups in the rates of stroke and systemic embolism and major bleeding were not significant. The efficacy and safety of apixaban for stroke prevention in patients of advanced age with AF was also demonstrated in a subanalysis of ARISTOTLE. ${ }^{69}$ An age of 65 years or older was associated with an increased risk of stroke and bleeding in patients with AF based on risk-stratification scales such as the $\mathrm{CHADS}_{2}$ and HAS-BLED. The sub-analysis found that the efficacy and safety of apixaban were consistent across patients with different levels of risk for stroke or bleeding.

\section{AVERROES}

Apixaban Versus acEtylsalicylic acid to pRevent stROke in AF patients who have failed or are unsuitablE for vitamin $\mathrm{K}$ antagoniSt treatment (AVERROES) ${ }^{70}$ was a NOAC study that included patients for whom warfarin treatment was unsuitable. The study included 5599 patients with AF who received apixaban ( $5 \mathrm{mg}$ twice daily, or $2.5 \mathrm{mg}$ twice daily in patients meeting specific criteria, as described for the ARISTOTLE trial) or aspirin. The mean age of the patients was 70 years and they had a mean $\mathrm{CHADS}_{2}$ score of 2.0.

The AVERROES trial was stopped early due to clear evidence of the benefit of apixaban over aspirin. ${ }^{70}$ Apixaban reduced the risk of stroke or systemic embolism by $55 \%$ 
compared with aspirin ( $1.6 \%$ vs $3.7 \%$ per year; HR, 0.45 ; 95\% CI, 0.32, 0.62; $P<0.001)$. Analysis of ischemic stroke risk showed a significant reduction for apixaban compared with aspirin ( $1.1 \%$ vs $3.0 \%$ per year; HR, 0.37 ; 95\% CI, 0.25, 0.55; $P<0.001)$. The risk of $\mathrm{ICH}$, hemorrhagic stroke, or major bleeding was not significantly different between the groups $(P=0.69,0.45$, and 0.57 , respectively). Rates of MI were similar between treatment groups $(P=0.59)$. Rates of all-cause mortality were $3.5 \%$ per year in the apixaban group and $4.4 \%$ per year in the aspirin group $(P=0.07)$.

For AVERROES, the effects of apixaban compared with aspirin in the older patient (age $\geq 75$ years) subgroups were consistent with effects in the overall study population..$^{70}$ Both apixaban and aspirin were well tolerated and no significant difference was observed for all-cause mortality rates $(3.5 \% \mathrm{vs}$ $4.4 \%$ per year; HR, $0.79 ; 95 \%$ CI, 0.62, $1.02 ; P=0.07$ ). Subgroup analysis showed that in patients treated with aspirin, the risk of stroke or systemic embolism was increased from $2.7 \%$ per year for those aged $65-74$ years to $6.1 \%$ per year for those aged $\geq 75$ years. The risk of major bleeding increased with age for both the aspirin and apixaban groups (aspirin: $0.5 \%$ per year for those aged $<65$ years compared with $2.2 \%$ per year for those aged $\geq 75$ years; apixaban: $0.7 \%$ per year for those aged $<65$ years compared with $2.6 \%$ per year for those aged $\geq 75$ years). This highlights the increased stroke risk in the elderly population.

\section{Practical considerations for NOAC use in older patients}

The NOACs have many benefits over warfarin for stroke prevention in patients with AF; however, treatment decisions also require an assessment of the practical considerations associated with these treatments including the need for dose adjustment in specific patients, cost-effectiveness, limitations in monitoring the extent of anticoagulation, and the lack of a specific reversal agent.

Such considerations are particularly important in the treatment of older patients, who may experience different reactions to drugs than younger patients. This is often due to older patients having poor renal clearance, a lower body weight, and polypharmacy. ${ }^{71}$ Dabigatran exposure may be up to 1.3times higher in the older population ( $\geq 75$ years compared with patients aged $65-75$ years). ${ }^{72}$ Rivaroxaban results in increased plasma concentration levels (1.5-times higher) in the population aged $\geq 65$ years compared with younger patients receiving the same dose. ${ }^{55}$ Apixaban exposure has been reported 1.3-times higher in patients aged $>65$ years. ${ }^{73}$
Due to the age-related variation in drug exposure, modified dosing may be required for some elderly patients; however, this is primarily based on an assessment of renal function rather than age, per se.

Community-level data will be helpful in understanding the benefits and risks of these agents and physicians have begun to make observations in the clinical setting. Bleeding rates both higher and lower than those seen in clinical trials have been observed, ${ }^{74,75}$ and one study noted higher rates of bleeding in patients $>75$ years of age..$^{75}$ The need for clarity around an optimal approach to dose adjustments with dabigatran and rivaroxaban for elderly patients, beyond the guidance currently provided in prescribing information will probably become more apparent as use of these agents in clinical practice increases. ${ }^{76}$ Patients taking apixaban should be treated with a lower dose (2.5 mg twice daily) when they meet at least 2 of the following characteristics: age $\geq 80$ years, body weight $\leq 60 \mathrm{~kg}$, or serum creatinine $\geq 1.5 \mathrm{mg} / \mathrm{dL}$. Therefore, elderly patients ( $\geq 80$ years) should receive $2.5 \mathrm{mg}$ twice daily if they also have body weight $\leq 60 \mathrm{~kg}$ or serum creatinine $\geq 1.5 \mathrm{mg} / \mathrm{dL}$. Realworld experience will also be valuable as apixaban is used in clinical practice.

Adherence to dosing regimens and monitoring requirements may be a particular challenge for the elderly. ${ }^{77}$ Patient education is required for elderly patients to highlight the importance of compliance, efficacy, and safety. ${ }^{71}$ Patients and physicians need to understand the various therapeutic options and the corresponding benefits and risks.

\section{Renal insufficiency}

Renal insufficiency may affect drug exposure in older patients. The selection of anticoagulant therapy must be individualized according to patient characteristics, needs, and perceived risk of stroke or bleeding. For example, prescribing information for dabigatran recommends dose adjustment for renal impairment and notes an increased bleeding risk among patients aged $>75$ years. ${ }^{54}$ There have been two reported cases of prolonged bleeding time (one fatal) for patients treated with dabigatran ${ }^{78}$; both patients were elderly with poor renal function and low body weight. In addition, a Japanese report identified 75 cases of serious bleeding in patients $>70$ years of age. Mortalities included eight patients aged $\geq 75$ years, seven of whom were $>80$ years old. ${ }^{79}$

Renal clearance of dabigatran is higher than that of rivaroxaban and apixaban. ${ }^{80}$ With dabigatran, in patients with a creatinine clearance $(\mathrm{CrCl})$ of $30-50 \mathrm{~mL} / \mathrm{min}$, 
there is a 2.7-fold increase in exposure compared with patients with $\mathrm{CrCl}$ of $97-137 \mathrm{~mL} / \mathrm{min}$, and lower dosing is recommended in these patients. ${ }^{54}$ Dabigatran is contraindicated in patients with severe renal impairment $(\mathrm{CrCl}<30 \mathrm{~mL} / \mathrm{min})$. With rivaroxaban in patients with a $\mathrm{CrCl}$ of $30-49 \mathrm{~mL} / \mathrm{min}$, there is a 1.5 -fold increase in exposure compared with patients with normal $\mathrm{CrCl}^{55}$ and a lower dose is recommended in patients with a $\mathrm{CrCl}$ of $15-50 \mathrm{~mL} / \mathrm{min}$. Rivaroxaban is not recommended for use in patients with a $\mathrm{CrCl}<15 \mathrm{~mL} / \mathrm{min}$. With apixaban, there is a 1.29-fold increase in exposure in patients with moderate renal impairment ( $\mathrm{CrCl}$ of $30-50 \mathrm{~mL} / \mathrm{min}$ ) but no dose adjustment for apixaban is required for patients with mild or moderate renal impairment and apixaban should be used with caution in patients with severe renal impairment ( $\mathrm{CrCl}$ of $15-29 \mathrm{~mL} / \mathrm{min}) .{ }^{56} \mathrm{As}$ described above, a lower dose of apixaban (2.5 mg twice daily) is indicated in patients meeting two of the following three criteria: age $\geq 80$ years, body weight $\leq 60 \mathrm{~kg}$, or serum creatinine $\geq 1.5$ $\mathrm{mg} / \mathrm{dL}$. A sub-analysis of the ARISTOTLE trial looking at patients with a $\mathrm{CrCl}$ of $25 \mathrm{~mL} / \mathrm{min}$ or higher divided into three different levels of renal function/impairment found that apixaban was more effective than warfarin at preventing stroke or systemic embolism and reducing mortality regardless of renal function. ${ }^{81}$

\section{Cost-effectiveness}

Several studies assessing the cost-effectiveness of dabigatran compared with warfarin in elderly patients have been published. These suggest that dabigatran is cost-effective relative to warfarin for stroke prevention in patients with AF. ${ }^{82-84}$ Based on patients aged $\geq 70$ years in the RE-LY trial, dabigatran $150 \mathrm{mg}$ twice daily was cost-effective compared with warfarin in patients at high risk of hemorrhage, in patients at high risk of stroke unless INR control was excellent, and in patients with a prior stroke or transient ischemic attack. ${ }^{82,83}$ This study also found warfarin to be cost-effective in patients at moderate risk for stroke (CHADS ${ }_{2}$ score of 1-2), unless hemorrhagic risk was high or time in therapeutic range was low $(<57.1 \%)$. In addition, rivaroxaban appears to be cost-effective compared with warfarin. ${ }^{85}$

Apixaban treatment also appears to be cost-effective. Among patients aged $\geq 70$ years with a history of prior stroke or transient ischemic attack, apixaban would be cost-effective relative to warfarin assuming that it is introduced at a price similar to that of dabigatran. ${ }^{86}$ Apixaban was also more effective and less costly than aspirin over a 10-year follow-up period based on a model developed using data from the AVERROES trial. ${ }^{87}$ A study evaluating medical cost reductions associated with the use of individual NOACs compared with warfarin from the US payer perspective found lower medical costs with use of the NOACs (dabigatran, rivaroxaban, and apixaban) relative to warfarin, with apixaban offering the most substantial reduction in medical cost. ${ }^{88}$

\section{Monitoring and reversal of anticoagulant effect}

Unlike the importance of monitoring INR with warfarin, routine monitoring is not required with NOACs, as they exhibit predictable therapeutic effects with fixed doses. ${ }^{80}$ The INR cannot be used to measure the anticoagulant activity of these agents and there are no commercially available tests to monitor anticoagulation intensity with NOACs. This limits options for assessing treatment adherence and presents challenges in emergencies (eg, when there is active bleeding or the need for urgent medical procedures).

The anticoagulant effects of warfarin can be reversed using vitamin $\mathrm{K}$ or prothrombin complex concentrates (PCCs). There is currently no such pharmacologic antidote for the NOACs, but their shorter half-lives mean that the anticoagulant effect wanes rapidly once treatment is discontinued ${ }^{54-56}$ and specific reversal agents are under development. It is possible that therapies such as recombinant factor VIIa and activated PCCs may be used to reverse the effects of direct factor $\mathrm{Xa}$ inhibitors and hemodialysis may be effective in removing dabigatran from the blood, ${ }^{89}$ but PCCs have not been shown to be effective. ${ }^{90}$ Activated PCCs mitigated the effect of rivaroxaban in healthy subjects ${ }^{90}$ and results from in vitro testing suggest that activated PCCs and recombinant factor VIIa may reverse the effect of apixaban. ${ }^{91}$ Control of the bleeding site, regular fluids, and routine monitoring are advised for moderate bleeding. Hemodialysis for dabigatran and PCCs to enhance thrombin generation should be considered for life-threatening bleeding. ${ }^{92,93}$

\section{Conclusion}

This review highlights the benefits of NOACs for the elderly population with AF; these novel agents reduce stroke risk in this population, providing a suitable alternative to warfarin. The results from large randomized clinical trials provide a broad evidence base for the use of new anticoagulant therapies in patients with non-valvular AF at risk of stroke. Although the NOACs are often discussed collectively, consid- 
eration of the pharmacologic properties of individual agents may help clinicians to identify the most appropriate agent for individual patients. Properties such as drug metabolism and route of elimination may be important considerations in the treatment of stroke prevention in AF in specific patient groups, such as older patients with decreased renal function.

Despite the effectiveness of warfarin at lowering stroke risk in the elderly, this treatment has several disadvantages such as food restrictions, drug interactions and the need for frequent monitoring. NOACs such as dabigatran, rivaroxaban and apixaban overcome many of these disadvantages. They have a rapid onset of action, predictable anticoagulant effects that remove the requirement for routine coagulation monitoring and a low risk of drug-drug and drug-food interactions. Although clinical trials have not been powered to investigate differences between treatment groups within subgroups of older and younger patients, emerging data suggest that these agents are safe and have efficacy in patients of advanced age. However, the reduction in stroke risk must be balanced against the increased risk of bleeding in older patients and an antidote to reverse the anticoagulant effect of NOACs does not currently exist. Elderly patients must be evaluated carefully for impaired renal function which may increase the risk of bleeding.

\section{Acknowledgments}

Editorial support was provided by Bernadette Janas, $\mathrm{PhD}$, and Meredith Kalish, MD, of Caudex Medical, and funded by Pfizer Inc and Bristol-Myers Squibb.

\section{Disclosure}

The author is an investigator for the RE-LY (Boehringer Ingelheim), ROCKET-AF (Bayer, Johnson \& Johnson), and ARISTOTLE (Bristol-Myers Squibb/Pfizer Inc) clinical trials. In addition, he has been involved in clinical trials in various therapeutic areas sponsored by Gilead Sciences, Inc; Boehringer Ingelheim Pharma GmbH and Co; Eli Lilly and Company; Forest Pharmaceuticals; BioCryst Pharmaceuticals; sanofi-aventis; Wyeth Research; Bristol-Myers Squibb; GlaxoSmithKline plc; Kowa; Pfizer Pharmaceuticals; Takeda Pharmaceuticals; Myogen; Akros Pharma, Inc; Novo Nordisk; Johnson and Johnson; Novartis; Alba; Mannkind Corporation; Ingenix, Inc; Auxilium; Ono Pharma USA, Inc; Merck; Amylin Pharmaceuticals; Acambis; AstraZeneca; Janssen Pharmaceutica; ScheringPlough; Perlegen; Kos; and Cubist Pharmaceuticals.
Editorial support for this article was funded by Pfizer Inc and Bristol-Myers Squibb.

\section{References}

1. Wolf PA, Abbott RD, Kannel WB. Atrial fibrillation as an independent risk factor for stroke: the Framingham Study. Stroke. 1991;22(8): 983-988.

2. Wang TJ, Massaro JM, Levy D, et al. A risk score for predicting stroke or death in individuals with new-onset atrial fibrillation in the community: the Framingham Heart Study. JAMA. 2003;290(8): 1049-1056.

3. Go AS, Hylek EM, Phillips KA, et al. Prevalence of diagnosed atrial fibrillation in adults: national implications for rhythm management and stroke prevention: the AnTicoagulation and Risk Factors in Atrial Fibrillation (ATRIA) Study. JAMA. 2001;285(18):2370-2375.

4. Benjamin EJ, Wolf PA, D'Agostino RB, Silbershatz H, Kannel WB, Levy D. Impact of atrial fibrillation on the risk of death: the Framingham Heart Study. Circulation. 1998;98(10):946-952.

5. Hannon N, Sheehan O, Kelly L, et al. Stroke associated with atrial fibrillation-incidence and early outcomes in the north Dublin population stroke study. Cerebrovasc Dis. 2010;29(1):43-49.

6. Kannel WB, Wolf PA, Benjamin EJ, Levy D. Prevalence, incidence, prognosis, and predisposing conditions for atrial fibrillation: populationbased estimates. Am J Cardiol. 1998;82(8A):2N-9N.

7. Miyasaka Y, Barnes ME, Bailey KR, et al. Mortality trends in patients diagnosed with first atrial fibrillation: a 21-year community-based study. J Am Coll Cardiol. 2007;49(9):986-992.

8. Penado S, Cano M, Acha O, Hernández JL, Riancho JA. Atrial fibrillation as a risk factor for stroke recurrence. Am J Med. 2003;114(3): 206-210.

9. Stewart S, Hart CL, Hole DJ, McMurray JJ. A population-based study of the long-term risks associated with atrial fibrillation: 20-year follow-up of the Renfrew/Paisley study. Am J Med. 2002;113(5):359-364.

10. Vidaillet H, Granada JF, Chyou PH, et al. A population-based study of mortality among patients with atrial fibrillation or flutter. Am J Med. 2002;113(5):365-370.

11. Fitzmaurice DA, Hobbs FDR, Jowett S, et al. Screening versus routine practice in detection of atrial fibrillation in patients aged 65 or over: cluster randomised controlled trial. BMJ. 2007;335(7616):383.

12. Gage BF, Waterman AD, Shannon W, Boechler M, Rich MW, Radford MJ. Validation of clinical classification schemes for predicting stroke: results from the National Registry of Atrial Fibrillation. JAMA. 2001;285(22):2864-2870.

13. Lip GY, Nieuwlaat R, Pisters R, Lane DA, Crijns HJ. Refining clinical risk stratification for predicting stroke and thromboembolism in atrial fibrillation using a novel risk factor-based approach: the Euro Heart Survey on atrial fibrillation. Chest. 2010;137(2):263-272.

14. Ho KK, Pinsky JL, Kannel WB, Levy D. The epidemiology of heart failure: the Framingham Study. J Am Coll Cardiol. 1993;22(4 Suppl A): 6A-13A.

15. National Center for Health Statistics. Blood Pressure Levels in Persons 18-74 Years of Age in 1976-1980, and Trends in Blood Pressure from 1960 to 1980 in the United States. Vital and Health Statistics, series 11. Washington DC: US Government Printing Office; 1986. DHHS publication 86-1684.

16. Wilson PW, Anderson KM, Kannel WB. Epidemiology of diabetes mellitus in the elderly. The Framingham Study. Am J Med. 1986;80(5A):3-9.

17. Sinnaeve PR, Brueckmann M, Clemens A, Oldgren J, Eikelboom J, Healey JS. Stroke prevention in elderly patients with atrial fibrillation: challenges for anticoagulation. J Intern Med. 2012;271(1):15-24.

18. Aguilar MI, Hart R. Oral anticoagulants for preventing stroke in patients with non-valvular atrial fibrillation and no previous history of stroke or transient ischemic attacks. Cochrane Database Syst Rev. 2005;3: CD001927.

19. van Walraven C, Hart RG, Connolly S, et al. Effect of age on stroke prevention therapy in patients with atrial fibrillation: the atrial fibrillation investigators. Stroke. 2009:40(4):1410-1416. 
20. Hylek EM, D'Antonio J, Evans-Molina C, Shea C, Henault LE, Regan S. Translating the results of randomized trials into clinical practice: the challenge of warfarin candidacy among hospitalized elderly patients with atrial fibrillation. Stroke. 2006;37(4):1075-1080.

21. Deplanque D, Leys D, Parnetti L, et al; SAFE II Investigators. Stroke prevention and atrial fibrillation: reasons leading to an inappropriate management. Main results of the SAFE II study. Br J Clin Pharmacol. 2004;57(6):798-806.

22. Go AS, Hylek EM, Borowsky LH, Phillips KA, Selby JV, Singer DE. Warfarin use among ambulatory patients with nonvalvular atrial fibrillation: the anticoagulation and risk factors in atrial fibrillation (ATRIA) study. Ann Intern Med. 1999;131(12):927-934.

23. Allen LaPointe NM, Governale L, Watkins J, Mulgund J, Anstrom KJ. Outpatient use of anticoagulants, rate-controlling drugs, and antiarrhythmic drugs for atrial fibrillation. Am Heart J. 2007;154(5): 893-898.

24. Brophy MT, Snyder KE, Gaehde S, Ives C, Gagnon D, Fiore LD. Anticoagulant use for atrial fibrillation in the elderly. $J$ Am Geriatr Soc. 2004;52(7):1151-1156.

25. Partington SL, Abid S, Teo K, Oczkowski W, O'Donnell MJ. Preadmission warfarin use in patients with acute ischemic stroke and atrial fibrillation: the appropriate use and barriers to oral anticoagulant therapy. Thromb Res. 2007;120(5):663-669.

26. Savage M, Teeling M, Bennett K, Feely J. Adherence to clinical guidance in the prescribing of oral antithrombotic medication in patients with atrial fibrillation. Ir J Med Soc. 2006;175(2):46-49.

27. Bristol-Myers Squibb. Coumadin ${ }^{\circledR}$ (warfarin sodium) [prescribing information]. New York, NY: Bristol-Myers Squibb; 2011. Available from: http://packageinserts.bms.com/pi/pi_coumadin.pdf. Accessed August 8, 2012.

28. Gattellari M, Worthington J, Zwar N, Middleton S. Barriers to the use of anticoagulation for nonvalvular atrial fibrillation: a representative survey of Australian family physicians. Stroke. 2008;39(1): $227-230$.

29. Reynolds MW, Fahrbach K, Hauch O, et al. Warfarin anticoagulation and outcomes in patients with atrial fibrillation: a systematic review and metaanalysis. Chest. 2004;126(6):1938-1945.

30. Esmerio FG, Souza EN, Leiria TL, Lunelli R, Moraes MA. Constant use of oral anticoagulants: implications in the control of their adequate levels. Arg Bras Cardiol. 2009;93(5):549-554.

31. Reynolds MR, Shah J, Essebag V, et al. Patterns and predictors of warfarin use in patients with new-onset atrial fibrillation from the FRACTAL Registry. Am J Cardiol. 2006;97(4):538-543.

32. Wan Y, Heneghan C, Perera R, et al. Anticoagulation control and prediction of adverse events in patients with atrial fibrillation: a systematic review. Circ Cardiovasc Qual Outcomes. 2008;1(2):84-91.

33. Baker WL, Cios DA, Sander SD, Coleman CI. Meta-analysis to assess the quality of warfarin control in atrial fibrillation patients in the United States. J Manag Care Pharm. 2009;15(3):244-252.

34. van Walraven C, Jennings A, Oake N, Fergusson D, Forster AJ. Effect of study setting on anticoagulation control: a systematic review and metaregression. Chest. 2006;129(5):1155-1166.

35. Masaki N, Suzuki M, Matsumura A, Maruyama Y, Hashimoto Y. Quality of warfarin control affects the incidence of stroke in elderly patients with atrial fibrillation. Intern Med. 2010;49(16):1711-1716.

36. Hobbs FD, Roalfe AK, Lip GY, Fletcher K, Fitzmaurice DA, Mant J; Birmingham Atrial Fibrillation in the Aged Investigators and Midland Research Practices Consortium Network. Performance of stroke risk scores in older people with atrial fibrillation not taking warfarin: comparative cohort study from BAFTA trial. BMJ. 2011;342:d3653.

37. Rutten FH, Hak E, Stalman WA, Verheij TJ, Hoes AW. Is treatment of atrial fibrillation in primary care based on thromboembolic risk assessment? Fam Pract. 2003;20(1):16-21.

38. Pisters R, Lane DA, Nieuwlaat R, de Vos CB, Crijns HJ, Lip GY. A novel user-friendly score (HAS-BLED) to assess 1-year risk of major bleeding in patients with atrial fibrillation: the Euro Heart Survey. Chest. 2010;138(5):1093-1100.
39. Gage BF, Yan Y, Milligan PE, et al. Clinical classification schemes for predicting hemorrhage: results from the National Registry of Atrial Fibrillation (NRAF). Am Heart J. 2006;151(3):713-719.

40. Fang MC, Go AS, Chang Y, et al. A new risk scheme to predict warfarin-associated hemorrhage: The ATRIA (Anticoagulation and Risk Factors in Atrial Fibrillation) Study. J Am Coll Cardiol. 2011; 58(4):395-401

41. Apostolakis S, Lane DA, Guo Y, Buller H, Lip GY. Performance of the HEMORR(2)HAGES, ATRIA, and HAS-BLED bleeding riskprediction scores in patients with atrial fibrillation undergoing anticoagulation: the AMADEUS (evaluating the use of SR34006 compared to warfarin or acenocoumarol in patients with atrial fibrillation) study. J Am Coll Cardiol. 2012;60(9):861-867.

42. Bond AJ, Molnar FJ, Li M, Mackey M, Man-Son-Hing M. The risk of hemorrhagic complications in hospital in-patients who fall while receiving antithrombotic therapy. Thromb J. 2005;3(1):1.

43. Man-Son-Hing M, Laupacis A. Anticoagulant-related bleeding in older persons with atrial fibrillation: physicians' fears often unfounded. Arch Intern Med. 2003;163(13):1580-1586.

44. Man-Son-Hing M, Nichol G, Lau A, Laupacis A. Choosing antithrombotic therapy for elderly patients with atrial fibrillation who are at risk for falls. Arch Intern Med. 1999;159(7):677-685.

45. Khreizat HS, Whittaker P, Curtis KD, Turlo G, Garwood CL. The effect of cognitive impairment in the elderly on the initial and long-term stability of warfarin therapy. Drugs Aging. 2012;29(4):307-317.

46. Fihn SD, Callahan CM, Martin DC, McDonell MB, Henikoff JG, White $\mathrm{RH}$. The risk for and severity of bleeding complications in elderly patients treated with warfarin. The National Consortium of Anticoagulation Clinics. Ann Intern Med. 1996;124(11):970-979.

47. Authors/Task Force Members, Camm AJ, Lip GY, et al. 2012 focused update of the ESC Guidelines for the management of atrial fibrillation: An update of the 2010 ESC Guidelines for the management of atrial fibrillation * Developed with the special contribution of the European Heart Rhythm Association. Eur Heart J. 2012;33(21):2719-2747.

48. Fuster V, Rydén LE, Cannom DS, et al. 2011 ACCF/AHA/HRS focused updated incorporated into the ACC/AHA/ESC 2006 guidelines for the management of patients with atrial fibrillation: a report of the American College of Cardiology/American Heart Association Task Force on Practice Guidelines developed in partnership with the European Society of Cardiology and in collaboration with the European Heart Rhythm Association and the Heart Rhythm Society. Circulation. 2011;123(10):e269-e367.

49. You JJ, Singer DE, Howard PA, et al; American College of Chest Physicians. Antithrombotic therapy for atrial fibrillation: Antithrombotic Therapy and Prevention of Thrombosis, 9th ed: American College of Chest Physicians Evidence-Based Clinical Practice Guidelines. Chest. 2012;141(Suppl 2):e531S-e575S

50. Sato H, Ishikawa K, Kitabatake A, et al; Japan Atrial Fibrillation Stroke Trial Group. Low-dose aspirin for prevention of stroke in low-risk patients with atrial fibrillation: Japan Atrial Fibrillation Stroke Trial. Stroke. 2006;37(2):447-451.

51. Olesen JB, Lip GY, Lindhardsen J, et al. Risks of thromboembolism and bleeding with thromboprophylaxis in patients with atrial fibrillation: A net clinical benefit analysis using a 'real world' nationwide cohort study. Thromb Haemost. 2011;106(4):739-749.

52. Mant J, Hobbs FDR, Fletcher K, et al. Warfarin versus aspirin for stroke prevention in an elderly community population with atrial fibrillation (the Birmingham Atrial Fibrillation Treatment of the Aged Study, BAFTA): a randomised controlled trial. Lancet. 2007;370(9586):493-503.

53. Rash A, Downes T, Portner R, Yeo WW, Morgan N, Channer KS. A randomised controlled trial of warfarin versus aspirin for stroke prevention in octogenarians with atrial fibrillation (WASPO). Age Ageing. 2007;36(2):151-156.

54. Boehringer Ingelheim. Pradaxa ${ }^{\circledR}$ (dabigatran etexilate mesylate) [prescribing information]. Ridgefield, CT: Boehringer Ingelheim; 2012. Available from: http://bidocs.boehringer-ingelheim.com/BIWebAccess/ ViewServlet.ser?docBase $=$ renetnt $\&$ folderPath $=/$ Prescribing $\% 20$ Information/PIs/Pradaxa/Pradaxa.pdf. Accessed February 25, 2013. 
55. Bayer Pharma. Xarelto ${ }^{\circledR}$ (rivaroxaban) [prescribing information]. Leverkusen: Bayer Pharma; 2011. Available from: http://www. xareltohcp.com/sites/default/files/pdf/xarelto_0.pdf\#zoom=100. Accessed February 25, 2013.

56. Bristol-Myers Squibb. Eliquis ${ }^{\circledR}$ (apixaban) [prescribing information]. Princeton, NJ: Bristol-Myers Squibb; 2012. Available from: http:// packageinserts.bms.com/pi/pi_eliquis.pdf. Accessed January 4, 2013.

57. Ruff CT, Braunwald E. Will warfarin ever be replaced? J Cardiovasc Pharmacol Ther. 2010;15(3):210-219.

58. Guyatt GH, Akl EA, Crowther M, Gutterman DD, Schuünemann HJ; American College of Chest Physicians Antithrombotic Therapy and Prevention of Thrombosis Panel. Executive summary: antithrombotic therapy and prevention of thrombosis, 9th ed: American College of Chest Physicians Evidence-Based Clinical Practice Guidelines. Chest. 2012;141:7S-47S.

59. Wann LS, Curtis AB, Ellenbogen KA, et al. 2011 ACCF/AHA/HRS focused update on the management of patients with atrial fibrillation (update on dabigatran): a report of the American College of Cardiology Foundation/American Heart Association Task Force on practice guidelines. J Am Coll Cardiol. 2011;57(11):1330-1337.

60. Connolly SJ, Ezekowitz MD, Yusuf S, et al; RE-LY Steering Committee and Investigators. Dabigatran versus warfarin in patients with atrial fibrillation. N Engl J Med. 2009;361(12):1139-1151.

61. Connolly SJ, Ezekowitz MD, Yusuf S, Reilly PA, Wallentin L; Randomized Evaluation of Long-Term Anticoagulation Therapy Investigators. Newly identified events in the RE-LY trial. NEngl J Med. 2010;363(19): 1875-1876.

62. Eikelboom JW, Wallentin L, Connolly SJ, et al. Risk of bleeding with 2 doses of dabigatran compared with warfarin in older and younger patients with atrial fibrillation: an analysis of the randomized evaluation of long-term anticoagulant therapy (RE-LY) trial. Circulation. 2011; 123(21):2363-2372.

63. Uchino K, Hernandez AV. Dabigatran association with higher risk of acute coronary events: meta-analysis of noninferiority randomized controlled trials. Arch Intern Med. 2012;172(5):397-402.

64. Hohnloser SH, Oldgren J, Yang S, et al. Myocardial ischemic events in patients with atrial fibrillation treated with dabigatran or warfarin in the RE-LY (Randomized Evaluation of Long-Term Anticoagulation Therapy) trial. Circulation. 2012;125(5):669-676.

65. Beasley BN, Unger EF, Temple R. Anticoagulant options-why the FDA approved a higher but not a lower dose of dabigatran. $N$ Engl J Med. 2011;364(19):1788-1790.

66. Patel MR, Mahaffey KW, Garg J, et al; ROCKET AF Investigators. Rivaroxaban versus warfarin in nonvalvular atrial fibrillation. $N$ Engl J Med. 2011;365(10):883-891.

67. Halperin JL, Wojdyla D, Piccini JP, et al. Efficacy and safety of rivaroxaban compared with warfarin among elderly patients with nonvalvular AF in the ROCKET-AF trial. Stroke. 2012;43:A148.

68. Granger CB, Alexander JH, McMurray JJ, et al; ARISTOTLE Committees and Investigators. Apixaban versus warfarin in patients with atrial fibrillation. $N$ Engl J Med. 2011;365(11):981-992.

69. Lopes RD, Al-Khatib SM, Wallentin L, et al. Efficacy and safety of apixaban compared with warfarin according to patient risk of stroke and of bleeding in atrial fibrillation: a secondary analysis of a randomised controlled trial. Lancet. 2012;380(9855):1749-1758.

70. Connolly SJ, Eikelboom J, Joyner C, et al; AVERROES Steering Committee and Investigators. Apixaban in patients with atrial fibrillation. N Engl J Med. 2011;364(9):806-817.

71. Gurwitz JH, Field TS, Harrold LR, et al. Incidence and preventability of adverse drug events among older persons in the ambulatory setting. JAMA. 2003;289(9):1107-1116.

72. Boehringer Ingelheim Limited. Pradaxa ${ }^{\circledR}$ (Dabigatran) [summary of product characteristics]. Electronic Medicines Compendium; updated September 21, 2012. Available from: http://www.medicines.org. uk/EMC/medicine/24839/SPC/Pradaxa+150+mg+hard+capsules/. Accessed January 3, 2013.
73. Bristol-Myers Squibb-Pfizer. Eliquis ${ }^{\circledR}$ (Apixaban) [summary of product characteristics]. Electronic Medicines Compendium; updated March 12, 2012. Available from: http://www.medicines.org.uk/EMC/ medicine/24988/SPC/Eliquis $+2.5+$ mg + film-coated+tablets/. Accessed February 3, 2012.

74. Parikh V, Chainani V, Howard M, et al. Is dabigatran safe in "real life"? J Am Coll Cardiol. 2012;59(13s1):E602.

75. Rajdev A, Bradley J, Petrini J, Alexander J. A community experience of the novel anticoagulant Pradaxa. J Am Coll Cardiol. 2012; 59(13s1):E601.

76. Skanes AC, Healey JS, Cairns JA, et al; Canadian Cardiovascular Society Atrial Fibrillation Guidelines Committee. Focused 2012 update of the Canadian Cardiovascular Society atrial fibrillation guidelines: recommendations for stroke prevention and rate/rhythm control. Can J Cardiol. 2012;28(2):125-136.

77. Kimmel SE, Chen Z, Price M, et al. The influence of patient adherence on anticoagulation control with warfarin: results from the International Normalized Ratio Adherence and Genetics (IN-RANGE) Study. Arch Intern Med. 2007;167(3):229-235.

78. Legrand M, Mateo J, Aribaud A, et al. The use of dabigatran in elderly patients. Arch Intern Med. 2011;171(14):1285-1286.

79. [Deaths of 15 patients as a side effect five months after commercial release: interim report survey]. National Purazakisa. 2011 Sept 28. Available from: http://www.mixonline.jp/tabid/55/artid/41434/Default. aspx. Accessed January 31, 2013. Japanese.

80. Eriksson BI, Quinlan DJ, Eikelboom JW. Novel oral factor Xa and thrombin inhibitors in the management of thromboembolism. Annu Rev Med. 2011;62:41-57.

81. Hohnloser SH, Hijazi Z, Thomas L, et al. Efficacy of apixaban when compared with warfarin in relation to renal function in patients with atrial fibrillation: insights from the ARISTOTLE trial. Eur Heart $J$. 2012;33(22):2821-2830.

82. Kamel H, Johnston SC, Easton JD, Kim AS. Cost-effectiveness of dabigatran compared with warfarin for stroke prevention in patients with atrial fibrillation and prior stroke or transient ischemic attack. Stroke. 2012;43(3):881-883.

83. Shah SV, Gage BF. Cost-effectiveness of dabigatran for stroke prophylaxis in atrial fibrillation. Circulation. 2011;123(22):2562-2570.

84. Freeman JV, Zhu RP, Owens DK, et al. Cost-effectiveness of dabigatran compared with warfarin for stroke prevention in atrial fibrillation. Ann Intern Med. 2011;154(1):1-11.

85. Lee S, Anglade MW, Pham D, Pisacane R, Kluger J, Coleman CI. Costeffectiveness of rivaroxaban compared to warfarin for stroke prevention in atrial fibrillation. Am J Cardiol. 2012;110(6):845-851.

86. Kamel H, Easton JD, Johnston SC, Kim AS. Cost-effectiveness of apixaban vs warfarin for secondary stroke prevention in atrial fibrillation. Neurology. 2012;79(14):1428-1434.

87. Lee S, Anglade MW, Meng J, Hagstrom K, Kluger J, Coleman CI. Cost-effectiveness of apixaban compared with aspirin for stroke prevention in atrial fibrillation among patients unsuitable for warfarin. Circ Cardiovasc Qual Outcomes. 2012;5(4):472-479.

88. Deitelzweig S, Amin A, Jing Y, et al. Medical cost reductions associated with the usage of novel oral anticoagulants vs warfarin among atrial fibrillation patients, based on the RE-LY, ROCKET-AF, and ARISTOTLE trials. J Med Econ. 2012;15(4):776-785.

89. De Caterina R, Husted S, Wallentin L, et al; Coordinating Committee. New oral anticoagulants in atrial fibrillation and acute coronary syndromes: ESC Working Group on Thrombosis-Task Force on Anticoagulants in Heart Disease position paper. $J$ Am Coll Cardiol. 2012;59(16): 1413-1425.

90. Eerenberg ES, Kamphuisen PW, Sijpkens MK, Meijers JC, Buller HR, Levi M. Reversal of rivaroxaban and dabigatran by prothrombin complex concentrate: a randomized, placebo-controlled, crossover study in healthy subjects. Circulation. 2011;124(14):1573-1579.

91. Escolar G, Arellano-Rodrigo E, Reverter JC, et al. Reversal of apixaban induced alterations of hemostasis by different coagulation factor concentrates: studies in vitro with circulating human blood. Circulation. 2012;126(4):520-521. 
92. Barillari G, Pasca S, Barillari A, De Angelis V. Emergency reversal of anticoagulation: from theory to real use of prothrombin complex concentrates. A retrospective Italian experience. Blood Transfus. 2012: 10(1):87-94.

93. Bruce D, Nokes TJ. Prothrombin complex concentrate (Beriplex P/N) in severe bleeding: experience in a large tertiary hospital. Crit Care. 2008;12(4):R105.
94. Wolf PA, Abbott RD, Kannel WB. Atrial fibrillation: a major contributor to stroke in the elderly. The Framingham Study. Arch Intern Med. 1987;147(9):1561-1564.

\section{Publish your work in this journal}

The International Journal of General Medicine is an international, peer-reviewed open-access journal that focuses on general and internal medicine, pathogenesis, epidemiology, diagnosis, monitoring and treatment protocols. The journal is characterized by the rapid reporting of reviews, original research and clinical studies across all disease areas.
A key focus is the elucidation of disease processes and management protocols resulting in improved outcomes for the patient. The manuscript management system is completely online and includes a very quick and fair peer-review system. Visit http://www.dovepress.com/ testimonials.php to read real quotes from published authors.

Submit your manuscript here: http://www.dovepress.com/international-journal-of-general-medicine-journal 